Adeoye-Isijola et al., Afr J Tradit Complement Altern Med., (2018) 15 (2): $42-50$

https://doi.org/10.21010/ajtcam.v15i2.6

\title{
BIOACTIVE COMPOUNDS IN ETHANOL EXTRACT OF LENTINUS SQUARROSULUS MONT - A NIGERIAN MEDICINAL MACROFUNGUS
}

\section{Morenike Olutunmbi Adeoye-Isijola ${ }^{1}$, Olufunmiso Olusola Olajuyigbe ${ }^{1,3^{*}}$, Segun Gbolagade Jonathan $^{2}$, Roger Murugas Coopoosamy ${ }^{3}$}

${ }^{1}$ Department of Microbiology, School of Sciences and Technology, Babcock University, PMB 4005, Ilisan Remo, Ogun State, Nigeria; ' Department of Botany, Faculty of Sciences, University of Ibadan, Ibadan, Oyo State, Nigeria; ${ }^{3}$ Department of Nature Conservation, Faculty of Natural Sciences, Mangosuthu University of Technology, Durban, South Africa

*Corresponding Author Email: funmijuyigbe12@yahoo.com

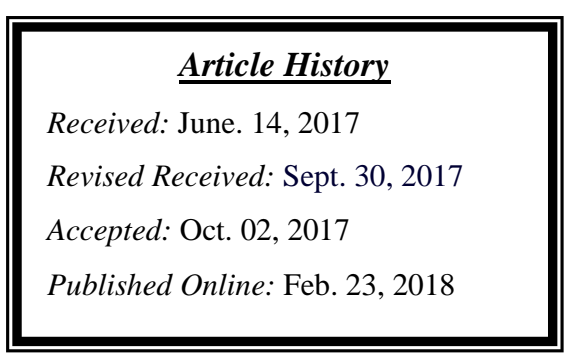

\begin{abstract}
Background: The continuous search for new lead compounds of therapeutic importance has become necessary in the face of treatment failures and multidrug resistance plaguing the world. While many plants and higher fungi are sources of bioactive compounds yet to be fully harnessed, understanding the bioactive components in macrofungus could serve as a lead for investigating its biological activities and medicinal potentials.

Materials and Methods: The bioactive compounds in the ethanolic extract of Lentinus Squarrosulus, an edible Nigerian macrofungus, were investigated by Gas Chromatography-Mass Spectrometry (GC-MS) analysis.

Results: There were nine bioactive compounds in this edible macrofungus. Of these compounds, 9,12-Octadecanoic acid ethyl ester (37.39\%; RT:39.815) was the highest in quantity, followed by Hexadecanoic acid ethyl ester (14.49\%; RT:36.550). Other fatty acids, their ethyl esters and other compounds identified included 2-Butenethioic acid,3(ethylthio)-S-(1-methylethyl) ester (4.51\%; RT:15.866), n-Hexadecanoic acid (4.74\%; RT:36.034), 9,12Octadecadienoic acid (Z,Z)- (11.88\%; RT:39.429), 9,17-Octadecadienal,(Z)- (5.01\%; RT:39.500), ethyl oleate (5.27\%; RT:39.898), 3a,6-Methano-3aH-indene,2,3,6,7 tetrahydro (4.04\%; RT:48.379), and 9,12-Octadecadienoic acid (Z,Z)-,2 hydroxy-1-(hydroxymethyl) ethyl ester (12.68\%; RT:48.682). Some of these compounds have antimicrobial, antioxidant, hepatoprotective, hypocholesterolemic as well as cancer preventive activities amongst others.

Conclusion: This study showed the bioactive components of therapeutic potentials in $L$. squarrosulus while creating a platform for screening, isolating and identifying many bioactive components which may be useful in the treatment of the various ailments, disorders and diseases in the nearest future.
\end{abstract}

Keywords: Bioactive constituents; ethanolic extract; Lentinus squarrosulus; GC-MS analysis; mushroom; macrofungi.

\section{Introduction}

Higher fungi including mushrooms have been part of the human diet for thousands of years (Cooke, 1977). Most mushrooms are very important nutritionally and are rich in protein, minerals and vitamins (Mattila et al., 2001; Rudawska and Leski, 2005). Of more than 200 species existing in nature, about 22 species are rigorously cultivated (Manzi et al., 2001). While many bioactive compounds affecting human and animal physiology have been identified in many mushrooms (Wang and $\mathrm{Ng}$, 2006), many species of mushrooms have therapeutic values including antihemorrhagic, anticholesterol, antitumor and anticancer properties (Zheng et al., 2010).

Lentinus squarrosulus (also referred to as Lentinus subnudus) is one of the most common Nigerian edible mushrooms. It grows wildly on decaying wood during the raining season from April to October. Its identifying features include its tough mixture of matured sporophores, velvety stipe and funnel-shaped whitish pileus (Jonathan, 2002). While its spores print is white and spore size ranged between $5-8$ and $2-4 \mu \mathrm{m}$ along the major and minor axis respectively (Jonathan, 2002), Lentinus subnudus belongs to the family polyporaceae which is the largest group of aphyllophorales (Pegler, 1983). Lentinus species grow naturally on some substrates and can be successfully cultivated on others (Gbolagade et al., 2006; Jonathan et al., 2010). 
Being edible, it can be prepared into a range of delicacies as they add flavour to food and act as condiments (Ohuoya and Etugo, 1993). Its meaty taste is a good alternative to animal protein among rural dwellers and average Nigerians who cannot afford the high cost of meat due to their financial status. Although indigenous mushrooms growing in the wild have been found to be nutritious and very important for medicinal purposes, many have been used as tea and nutritional food for their special fragrance and texture purposes (Manzi et al., 1999). Most of them are very good sources of amino acids, ascorbic acid, glycogen, lipid, sugar and vitamins and minerals such as calcium, iron, phosphorus, potassium, sodium, magnesium and zinc (Moa and Jica, 2000; Oei, 2003; Jonathan et al., 2011; Kumari et al., 2011).

Although the nutritional values and taste components of many mushrooms have been reported by Yang et al. (2001), there is a dearth of information on the bioactive compounds in extracts of mushrooms especially as regards those of Lentinus species. While plants and higher fungi are large sources of bioactive compounds serving as lead to develop novel drugs (Cowan, 1999) and about $80 \%$ of the world population depends on natural products for their health maintenance due to minimal side effects and cost effectiveness (Jagtap et al., 2009), understanding the bioactive components in this macrofungus could serve as a lead for investigating its biological activities and medicinal potentials. Consequently, determining the bioactive compounds of the extract by using Gas Chromatography-Mass Spectrometry (GC-MS) becomes inevitable. The combination of the separation technique (GC) with the best identification technique (MS) makes GC-MS an ideal technique for qualitative and quantitative analysis for volatile and semi-volatile compounds. This study, therefore, aims at utilizing a rapid method, Gas Chromatography-Mass Spectrometry (GC-MS) technique, for quantitative determination of bioactive compounds in Lentinus squarrosulus Mont. in view of the fact that higher fungi remain a vast and a large source of new pharmaceutical products yet to be explored. This is to ultimately discover and identify new safe drugs which are devoid of side effects and are active against a wide range of diseases.

\section{Materials and Methods \\ Collection of mushroom materials and identification}

Several batches of fresh fruiting body of the macrofungus, L. Squarrosulus, growing on a decaying tree stump of Mangifera indica were collected from Odogbolu, Ogun state, Nigeria between April and June, 2014 and identified using the standard descriptions of Alexopoulos et al. (1996). This identification was further authenticated by Professor S.G. Jonathan, of the Department of Botany, University of Ibadan, and Ibadan, Nigeria. A voucher specimen (BU001/0817) was deposited at the Herbarium of Babcock University. The mushroom samples were dried, powdered and stored in air-tight amber bottle and refrigerated at $04^{\circ} \mathrm{C}$ for future uses.

\section{Extraction procedure}

Two hundred gram (200 g) of the crude powdered sample of L. squarrosulus (shown in Figure 1) was soaked in ethanol usually used traditionally in preparing herbal medicines and agitated continuously over $72 \mathrm{~h}$. It was then filtered through Whatman No. 1 filter paper. The extract was then concentrated using a rotary evaporator.

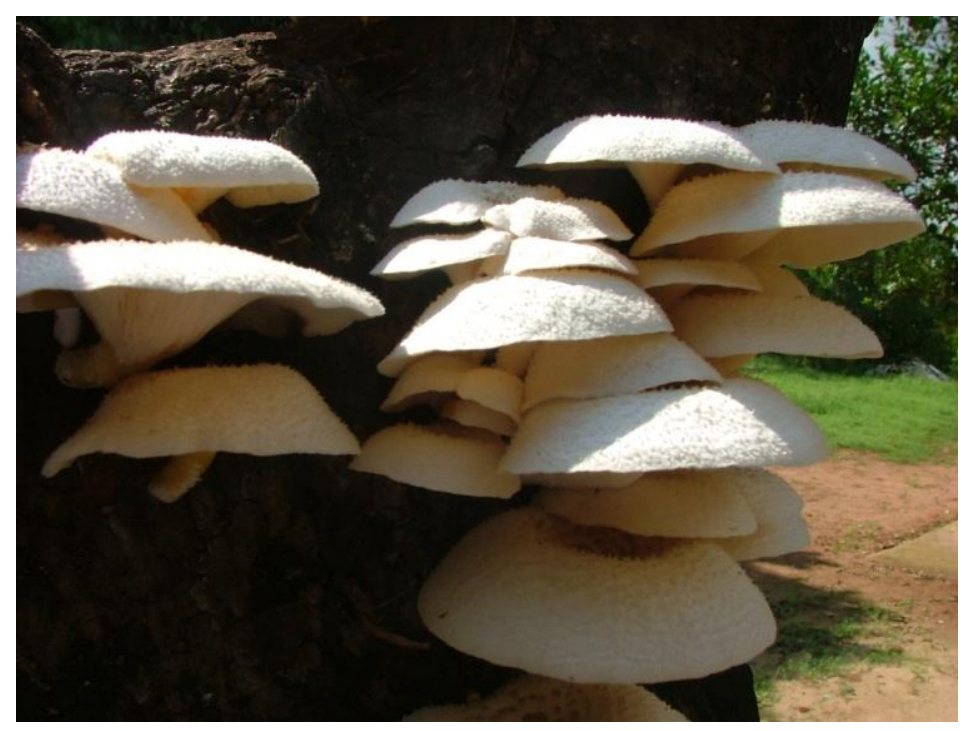

Figure 1: Lentinus squarrosulus (Mont) growing on a decaying tree stump of Mangifera indica in Nigeria 


\section{Gas Chromatography-Mass Spectrum analysis (GC-MS) of mushroom ethanolic extract}

GC-MS analysis was carried out on a GC clarus 500 Perkin Elmer system with an AOC-20I auto sampler and gas chromatograph interfaced to a mass spectrophotometer instrument employing the following conditions: Column Elite- 1 fused silica capillary column $(30 \mathrm{~mm} \times 0.25 \mathrm{~mm} \mathrm{I.D} \times 1 \mu \mathrm{M}$ df, composed of $100 \%$ Dimethyl poly siloxane), operating in electron impact mode at $70 \mathrm{eV}$ helium (99.999\%) was used as carrier gas at a constant flow of $1 \mathrm{ml} / \mathrm{min}$ and an injection volume of $0.5 \mu \mathrm{l}$ was employed (split ratio of $10: 1$ ) injector temperature $250^{\circ} \mathrm{C}$; ion-source temperature $280^{\circ} \mathrm{C}$. The oven temperature was programmed from $110^{\circ} \mathrm{C}$ (isothermal for 2 min), with an increase of $10^{\circ} \mathrm{C} / \mathrm{min}$, to $200^{\circ} \mathrm{C}$, then $5^{\circ} \mathrm{C} / \mathrm{min}$ to $280^{\circ} \mathrm{C}$, ending with a $9 \mathrm{~min}$ isothermal at $280^{\circ} \mathrm{C}$. Mass spectra were taken at 70 $\mathrm{eV}$; a scan interval of $0.5 \mathrm{~s}$ and fragments from 45 to $450 \mathrm{Da}$. Total GC running time was $60 \mathrm{~min}$.

\section{Identification of components}

To identify the name, structure and molecular weight of the bioactive compounds in the mushroom, the spectra of the bioactive components in the extract were compared with the spectra of known components in the database of National Institute of Standard and Technique (NIST) with more than 62,000 patterns.

\section{Results}

In this study, nine bioactive compounds were identified in the ethanolic extract of the fruiting body of Lentinus squarrosulus by GC-MS analysis. The compounds identified were 2-Butenethioic acid, 3-(ethylthio) -, S-(1methylethyl) ester, n-Hexadecanoic acid (Palmitic acid); Hexadecanoic acid ethyl ester (Palmitic acid ethyl ester), 9,12Octadecadienoic acid (Z,Z)- (Linoleic acid), 9,17-Octadecadienal, (Z)-, 9,12 Octadecadienoic acid ethyl ester (Linolelaidic acid, ethyl ester), Ethyl Oleate (Oleic acid ethyl ester), 3a,6-Methano-3aH-indene,2,3,6,7-tetrahydro- and 9,12-Octadecadienoic acid (Z-Z)-,2-hydroxy-1-(hydroxymethyl) ethyl ester (2-monolinolein). While the chromatogram of the different bioactive components of the ethanolic extract of Lentinus squarrosulus is shown in Figure 2, the Retention Time (RT), name of the bioactive compounds, Peak Area (\%), Molecular Formula (MF) and molecular weight (MW), are as shown in Table 1.

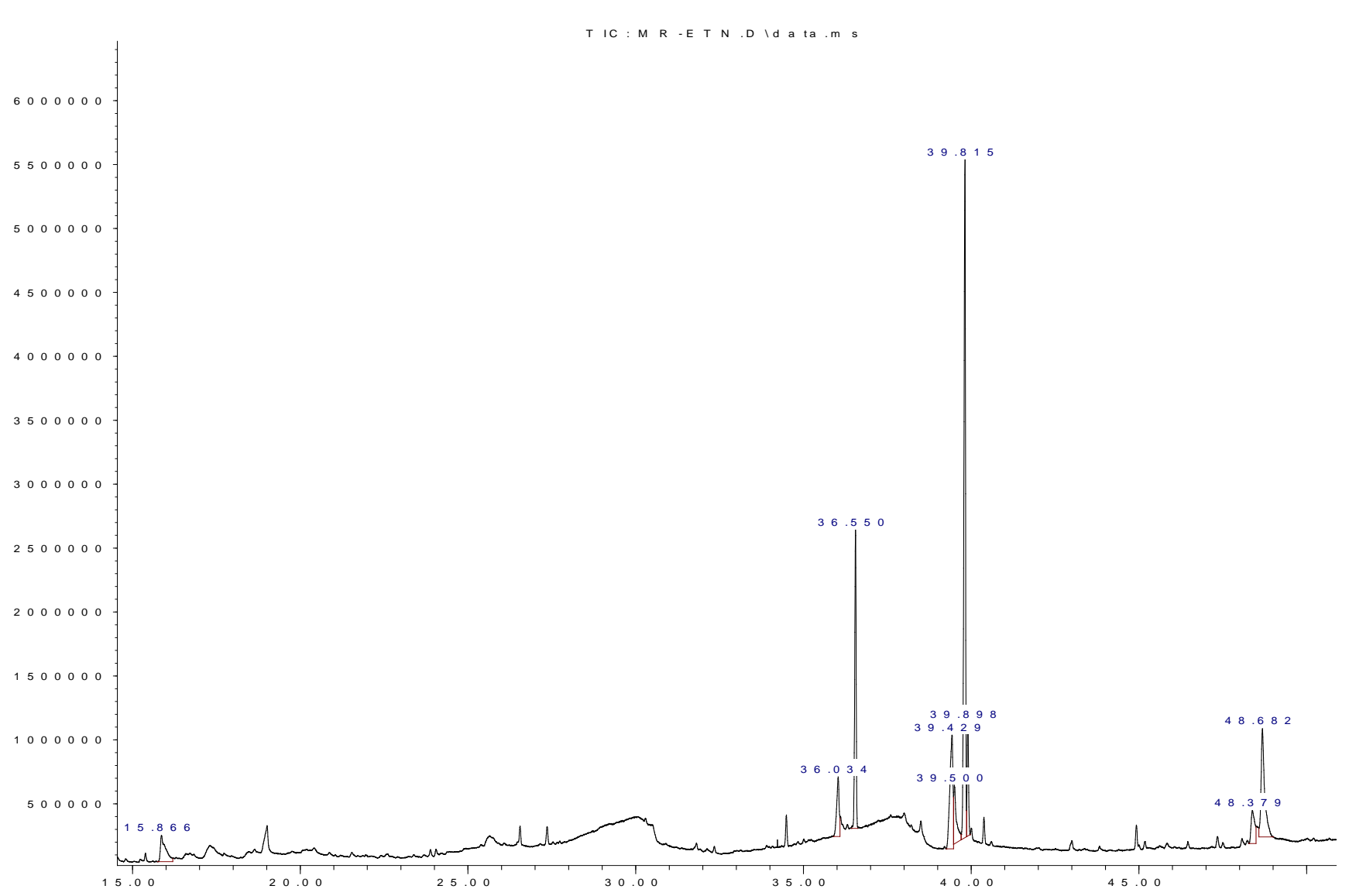

Figure 2: GC-MS spectrum of the ethanolic extract of Lentinus squarrosulus 
Table 1: Chemical composition of L. Squarrosulus using Gas Chromatography Mass Spectrometry (GC-MS)

\begin{tabular}{|c|c|c|c|c|c|}
\hline S/no. & RT (min) & Name of the Compound & (MF) & (MW) & $\begin{array}{l}\text { PA } \\
(\%)\end{array}$ \\
\hline 1. & 15.866 & 3-(ehylthio), S-(1-methylethyl) - 2-Butenethioic acid ester & $\mathrm{C}_{8} \mathrm{H}_{14} \mathrm{OS}$ & 158.26 & 4.51 \\
\hline 2. & 36.034 & n-Hexadecanoic acid (Palmitic acid) & $\mathrm{C}_{16} \mathrm{H}_{32} \mathrm{O}_{2}$ & 256.42 & 4.74 \\
\hline 3. & 36.550 & Hexadecanoic acid ethyl ester & $\mathrm{C}_{18} \mathrm{H}_{36} \mathrm{O}_{2}$ & 284.48 & 14.49 \\
\hline 4. & 39.429 & 9,12-Octadecadienoic acid (Z,Z)- (Linoleic acid) & $\mathrm{C}_{18} \mathrm{H}_{32} \mathrm{O}_{2}$ & 280.45 & 11.88 \\
\hline 5. & 39.500 & 9,17 -Octadecadienal, $(\mathrm{Z})-$ & $\mathrm{C}_{18} \mathrm{H}_{32} \mathrm{O}$ & 264.45 & 5.01 \\
\hline 6. & 39.815 & 9,12-Octadecadienoic acid, ethyl ester (Linoleic acid ethyl ester) & $\mathrm{C}_{20} \mathrm{H}_{36} \mathrm{O}_{2}$ & 308.50 & 37.39 \\
\hline 7. & 39.898 & Ethyl Oleate (Oleic acid ethyl ester) & $\mathrm{C}_{20} \mathrm{H}_{38} \mathrm{O}_{2}$ & 310.51 & 5.27 \\
\hline 8. & 48.379 & 3a,6-Methano-3aH-indene,2,3,6,7-tetrahydro- & $\mathrm{C}_{10} \mathrm{H}_{12}$ & 132.20 & 4.04 \\
\hline 9. & 48.682 & 9,12-Octadecadienoic acid (Z,Z)-,2-hydroxy-1-(hydroxymethyl) ethyl ester (2-Monolinolein) & $\mathrm{C}_{21} \mathrm{H}_{38} \mathrm{O}_{4}$ & 354.52 & 12.68 \\
\hline
\end{tabular}

Key: RT = Retention Time; MW = Molecular weight; MF = Molecular Formular; PA = Peak Area

From Table 2, the biological/therapeutic activities of the different component of the extracts are presented. While the nature and therapeutic potentials of $3 a, 6-$

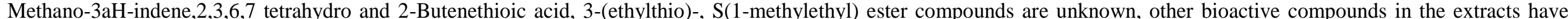

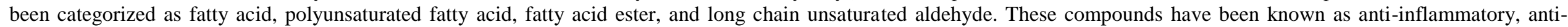

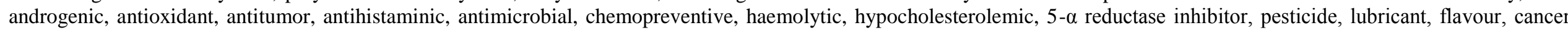
preventive, immunostimulant, hepatoprotective, antieczemic, antiacne, antiarthritic, antiandrogenic, anticoronary, lipo-oxygenase inhibitor, insectifuge and nematicide. 


\section{methylethyl) ester}

n-Hexadecanoic acid (Palmitic acid)

Fatty acid

3. Hexadecanoic acid ethyl ester (Palmitic Fatty acid ester acid ester)

\section{9,12-Octadecadienoic acid \\ (Conjugated Linoleic acid)}

(Z,Z)- Polyunsaturated Fatty acid
5. 9,17-Octadecadienal,(Z)-

Long chain unsaturated
aldehyde

\section{i-PrS $-\stackrel{\mathrm{C}}{\|} \mathrm{CH}=\mathrm{CMe} 2$}

CAS No. 34365-79-2

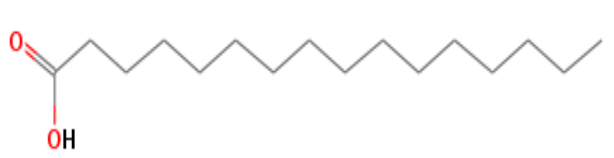

CAS No. 57-10-3

PubChem CID: 985

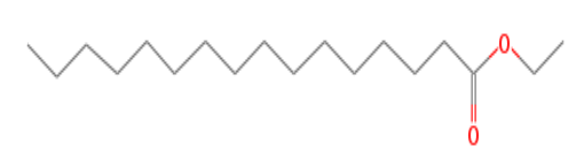

CAS No. 628-97-7

PubChem CID: 12366

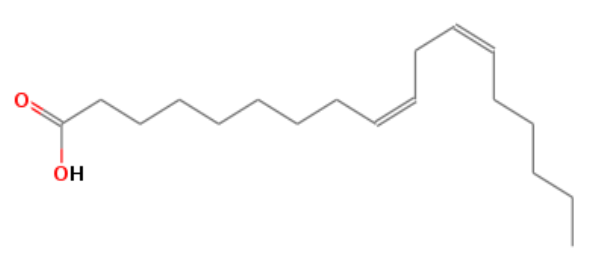

CAS No. 60-33-3

PubChem CID: 3931

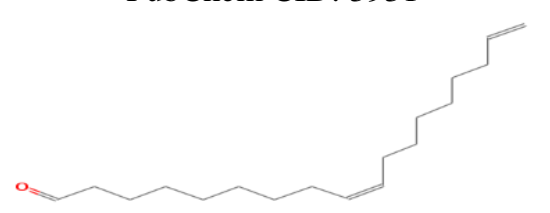

Antioxidant, antibacterial, nematicide,

inflammatory,

hypocholesterolemic,

pesticide, lubricant, antiandrogenic, antitumor, flavour, cancer preventive, immunostimulant, chemopreventive, haemolytic $5-\alpha$ reductase inhibitor, lipooxygenase inhibitor.

Antioxidant,

hypocholesterolemic, flavour, nematicide, pesticide, lubricant, anti-androgenic, haemolytic 5- $\alpha$ reductase inhibitor

Anti-inflammatory,

hypocholesterolemic, cancer preventive, hepatoprotective, nematicide, insectifuge(cide), antihistaminic, antieczemic, antiacne, 5- $\alpha$ reductase inhibitor, antiandrogenic, antiarthritic, anti coronary, antimicrobial.

Anti-inflammatory, antioxidant. 
9. 9,12-Octadecadienoic acid (Z,Z)-, 2 Fatty acid ester hydroxy-1-(hydroxymethyl) ethyl ester

(2-monolinolein)
6. 9,12-Octadecadienoic acid, ethyl ester Fatty acid ester (Linolelaidic acid ethyl ester)

7. $\quad$ Ethyl oleate (Oleic acid ethyl ester)

Fatty acid ester

PubChem CID: 5365672

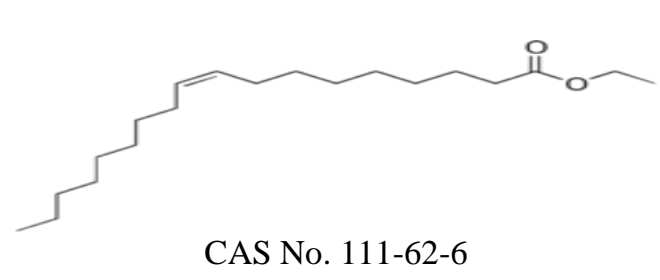

PubChem CID: 5363269

8. $3 \mathrm{a}, 6-$ Methano-3aH-indene, $2,3,6,7$

tetrahydro

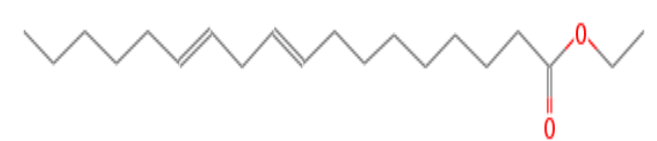

CAS No. 56554-35-9

PubChem CID: 5365667

Hypocholesterolemic,

nematicide,

hepatoprotective,

antiandrogenic, 5- $\alpha$ reductase inhibitor, antihistaminic anticoronary, insectifuge, antieczemic, antiacne,

antimicrobial.

Antimicrobial

\section{Still Unknown}

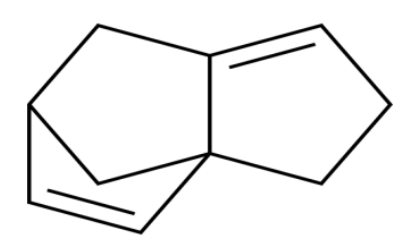

CAS No.: 98640-29-0

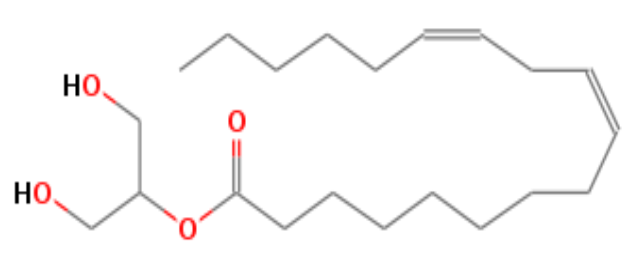

Hypocholesterolemic,

antieczemic, nematicide, hepatoprotective, antioxidant, antiacne, haemolytic,

CAS No. 3443-82-1

PubChem CID: 5365676 


\section{Discussion}

Mushrooms are macrofungi with a distinctive fruiting body large enough to be seen with the naked eyes. It includes both edible and non-edible species. Some macrofungi serve as food because of their nutrient content while some have been used extensively in traditional medicine (Nwachukwu and Uzoeto, 2010). The compounds in the ethanolic extract of the macrofungus used in this study are fatty acids and their ethyl esters. Others include compounds whose biological activities are still unknown. In searching for new therapeutic alternatives, macrofungi have shown different therapeutic activity including anti-plasmodium, anti-diabetic, anti-inflammatory, anti-carcinogenic, anti-viral, anti-microbial activities and immune-suppression (Imtiaj and Lee, 2007; David et al., 2012). While medicinal properties of higher fungi have been studied extensively, literature is sparse in documenting the bioactive components of pharmacological importance in Lentinus Squarrosulus (Mont) Singer, a Nigerian edible macrofungus. In this study, L. squarrosulus was found to have bioactive compounds with great therapeutic activities such as antioxidant, hypocholesterolemic, antimicrobial, antitumor, anti-inflammatory, antiarthritic, anticoronary, antieczemic, nematicide, antiacne and hepatoprotective amongst others.

The GC-MS spectra of the ethanolic extract of Lentinus squarrosulus showed different bioactive compounds of varying pharmacological relevance. These compounds include palmitic acid and its ethyl ester, linoleic acid and its ethyl ester as well as oleic acid ethyl ester. Quantitatively, linoleic acid and its ester was the highest in quantity (58\%), followed by the ethyl ester of hexadecanoic acid (14.49\%) ethyl ester of 9,12-Octadecadienoic acid (Z,Z)-,2-hydroxy1-(hydroxymethyl) ethyl ester (12.68\%). While 3a,6-Methano-3aH-indene,2,3,6,7-tetrahydro- was the least in quantity (4.01\%) and 3-(ehylthio), S-(1-methylethyl) - 2-Butenethioic acid ester was (4.51\%), n-Hexadecanoic acid was $4.71 \%$ and 9,17-Octadecadienal, (Z)- was 5.01\%. Although the pharmacological activities of 3-(ehylthio), S-(1-methylethyl) 2-Butenethioic acid ester and 3a,6-Methano-3aH-indene,2,3,6,7-tetrahydro- are still unknown, there are significant differences between linoleic acid and its ethyl ester and those of palmitic acid and its ethyl ester.

Although fatty acids have various therapeutic activities including anti-inflammatory and antioxidant activities (Kapoor and Huang, 2006; Galli and Calder, 2009; Poudel-Tandukar et al., 2009), omega-6, -7, -9 (N-6, N-7, N-9) fatty acids are important dietary nutrients providing numerous health benefits for humans (Santos et al., 1995; Harris, 2010). While N-6 fatty acids cannot be produce de novo in the body, the N-6 polyunsaturated fatty acids can be obtained from vegetable oils (Linoleic acid), egg yolk and organ meats (Whelan and McEntee, 2004). The N-7 mono-unsaturated fatty acids such as palmitoleic acid occur naturally in healthy skin (Spahis et al., 2008). The N-9 mono-unsaturated fatty acid such as oleic acid is a major fatty acid in olive oil. It is able to lower cholesterol levels and reduce atherosclerosis (Nicolosi et al., 2004).

Considering the therapeutic potentials of these bioactive compounds, it is important to indicate that diets in the western world lacking advantageous amounts of N-3 and N-9 fatty acids and contributing to an unhealthy diet rich in N-6 poly-unsaturated fatty acids are gaining popularity in Nigeria (Simopoulos, 2002). Therapeutically, N-3 and N-6 polyunsaturated fatty acids play multiple roles in blood clotting, blood pressure lowering, controlling of inflammation, cell membrane structure and lipid metabolism (Wijendran and Hayes, 2004). An unacceptable balance of these omega fatty acids could contribute to occurrence of different chronic diseases including heart disease, cancer, asthma and arthritis (Darveau et al., 2000; Huang and Ebersole, 2010).

The polyunsaturated fatty acid, 9,12-Octadecadienoic acid (Z-Z)-,2-hydroxy-1-(hydroxymethyl) ethyl ester (LA), is a conjugated linoleic acid known as an oxidant which can protect membranes form harm (Ha et al., 1990). Clinical studies have demonstrated that gamma linoleic acid (GLA), found primarily in evening primrose oil, may reduce joint pain, swelling and morning stiffness associated with rheumatoid arthritis (Allayee et al., 2009). This study, therefore, suggests that in the absence of evening primrose oil, a diet in which L. squarrosulus is incorporated could perform the same therapeutic activities.

\section{Conclusion}

In conclusion, the major components of the ethanolic extract of L. Squarrosulus, as indicated in this study, the extract of Lentinus squarrosulus contains bioactive compounds of numerous biological or therapeutic importance. The nine phytochemical constituents identified by the GC-MS analysis are, therefore, medicinally valuable and possess various pharmaceutical applications. That n-Hexadecanoic acid can inhibit haemolytic 5- $\alpha$ reductase implies that $L$. squarrosulus might have a liver disorder curing effect while the anti-inflammatory activity of some of these bioactive compounds would relieve sprained joints and general body pains. The findings strongly suggest that incorporating the extracts of L. squarrosulus, a Nigerian edible macrofungi, into the diet and drug formulations will have tremendous health benefits. A toxicological analysis of the identified bioactive compounds would be of necessity to develop safe drugs while further research to optimally extract the bioactive compounds in L. squarrosulus is ongoing. It is obvious from this study that L. squarrosulus holds a promise for the isolation and purification of novel pharmaceuticals.

Conflict of Interest: The authors hereby declare that there is no conflict of interest

Authors' contributions: All authors contributed equally to this study and have agreed together to submit this manuscript to AJTCAM. 


\section{References}

1. Alexopoulos, C. J., Mims, C. W. and Blackwell, M. (1996). Introductory mycology. Wiley, New York, New York, USA.

2. Allayee H., Roth, N. and Hodis, H. N. (2009). Polyunsaturated fatty acids and cardiovascular disease: implications for nutrigenetics. J. Nutrigenet. Nutrigenom., 2: 140-148.

3. Cooke, R. C. (1977). Fungi, Man and his Environment. Largman, London, New York, pp. 144.

4. Cowan, M. M. (1999). Plant products antimicrobial agents. Clin. Microbiol. Rev., 14: 564-584.

5. Darveau, R. P., Tanner, A. and Page, R. C. (2000). The microbial challenge in periodontitis. Periodontol., 14: 12-32.

6. David, O. M., Fagbohun, E. D., Oluyege, A. O. and Adegbuyi, A. (2012). Antimicrobial activity and physiochemical property of oils from tropical macrofungi. J. Yeast and Fungal Res., 3(1): 1-6.

7. Galli, C. and Calder, P. C. (2009). Effects of fat and fatty acid intake on inflammatory and immune responses: a critical review. Ann. Nutrit. Metab., 55: 123-39.

8. Gbolagade, J. S., Fasidi, I. O., Ajayi, E. J. and Sobowale, A. A. (2006). Effect of physico-chemical factors and semi synthetic media on vegetative growth of Lentinus subnudus (Berk.), an edible mushroom from Nigeria. Food Chem., 99: 742-747.

9. Ha, Y. L., Storkson, P. M. and Pariza, M. W. (1990). Inhibition of Benzo( $\alpha$ )pyrene-induced mouse for stomach neoplasia by conjugate dienoic derivatives of linoleic acid. Cancer Res., 50: 1097-1101.

10. Harris, W. (2010). Omega-6 and Omega-3 fatty acids: partners in prevention. Curr. Opin. Clin. Nutr. Metab. Care., 13: $125-9$.

11. Huang, C. B. and Ebersole, J. L. (2010). A novel bioactivity of omega-3 polyunsaturated acids ( n-3 PUFA) and their ester derivatives. Mol. Oral Microbiol., 25: 75-80.

12. Imtiaj A. and Lee, T. S. (2007). Screening of antimicrobial and antifungal activities from Korean wild mushrooms. World J. Agric. Sci., 3(3): 316-321.

13. Jagtap, N. S., Khadabadi, S. S., Ghorpade, D. S., Banarase, N. B. and Naphade, S. S. (2009). Antimicrobial and antifungal activity of Centella asiatica (L.) Urban Umbeliferae. Res. J. Pharm. Tech., 2: 328-30

14. Jonathan, S. G., Akinyemi, A. and Adenipekun, C. O. (2010). Biodegradation and digestibility of maize husks treated with edible fungi, Pleutotus tuber-regium and Lentinus subnudus from Nigeria. Elect. J. Env. Agric. Food Chem. EJEAFChe., (9)4: 742-750.

15. Jonathan, S. G., Amos Tautina B. M. V. and Olawuyi, O. J. (2011). Detection of exopolysaccharides in Lentinus squarrosulus (Berk.), a Nigerian mushroom. Afr. J. Agric. Res., 6(13): 3007-3012.

16. Kapoor, R. and Huang, Y. S. (2006). Gamma linolenic acid: an anti-inflammatory omega-6 fatty acid. Curr. Pharm. Biotechnol., 7: 531-4

17. Kumari, D., Reddy, M. S. and Upadhyay, R. C. (2011). Nutritional composition and antioxidant activities of 18 different wild Cantharellus mushrooms of Northwestern Himalayas. Food Sci. Tech. Int., 17: 557-567.

18. Manzi, P., Aguzzi, A. and Pizzoferrato L. (2001). Nutritional value of mushrooms widely consumed in Italy. Food Chem., 73: 321-325.

19. Manzi, P., Gambelli, L., Marconi, S., Vivanti, V. and Pizzoferrato, L. (1999). Nutrients in edible mushroom: An interspecies comparative study. Food Chem., 65: 477- 482.

20. Mattila, P., Konko, K., Eurola, M., Pihlawa, J.M., Astola, J., Vahteristo, V., Hietaniemi, J., Kumpulainen, J., Valtonen, M. and Piironen, V. (2001). Contents of vitamins, mineral elements and some phenolic compounds in the cultivated mushrooms. J. Agric. Food Chem., 49: 2343-2348.

21. Moa, S. and Jica, N. (2000) Local and export vegetables growing manual, Ministry of agriculture and Japan international co-operation agency, Agricultural Information Centre, Nairobi, p. 1-21.

22. Nicolosi, R. J., Woolfrey, B., Wilson, T. A., Scollin, P., Handelman, G. and Fisher, R. (2004). Decreased aortic early atherosclerosis and associated risk factors in hypercholesterolemic hamsters fed a high- or mid-oleic acid oil compared to a high-linoleic acid oil. J. Nutr. Biochem., 15: 540-547.

23. Nwachukwu, E. and Uzoeto, H. O. (2010). Antimicrobial activity of some local mushrooms on pathogenic isolates. J. Med. Plants Res., 4(23): 2460-2465.

24. Oei, P. (2003). Mushroom cultivation 3rd Edition. Appropriate Technology for mushroom growers. Backhuys Publishers, Leiden, The Netherlands.

25. Ohuoya, J. A. and Etugo, J. E. (1993). Studies of the cultivation of Pleurotus tuberregium (FR) Sing. an edible mushroom. Biores. Technol., 44: 1-3.

26. Poudel-Tandukar, K., Nanri, A., Matsushita, Y., Sasaki, S., Ohta, M., Sato, M. and Mizoue, T. (2009). Dietary intakes of alpha-linolenic and linoleic acids are inversely associated with serum C-reactive protein levels among Japanese men. Nutr., 29: 363-70

27. Rudawska, M., and Leski T. (2005). Macro and micro elemental contents in fruiting bodies of wild mushrooms from the Netecka forest in West-Central Poland. Food Chem., 92: 499-502.

28. Simopoulos, A. P. (2002). The importance of the ratio of omega-6/omega-3 essential fatty acids. Biomed. Pharmacother., 56: 365-379.

29. Spahis, S., Vanasse, M., Belanger, S.A., Ghadirian, P., Grenier, E. and Levy, E. (2008). Lipid profile, fatty acid composition and pro- and anti-oxidant status in pediatric patients with attention-deficit/hyperacticity disorder. Prostaglandins Leukot Essent Fatty Acids, 79: 47-53. 
30. Wang, $\mathrm{H}$. and $\mathrm{Ng}, \mathrm{T}$. B. (2001). Isolation and characterization of velutin, a novel low-molecular-weight ribosomeinactivating protein from winter mushroom (Flammulina velutipes) fruiting bodies. Life Sci., 68(18): 2151-58

31. Whelan, J. and McEntee, M. F. (2004). Dietary (n-6) PUFA and Intestinal Tumorigenesis. J. Nutr., 134: 3421S-3426S.

32. Wijendran, V. and Hayes, K.C. (2004). Dietary n-6 and n-3 fatty acid balance and cardiovascular health. Annual Review of Nutrition, 24, 597-615.

33. Yang, J. H., Lin, H. C. and Mau, J. L. (2001) Non-volatile taste components of several commercial mushrooms. Food Chem., 72: 465-471

34. Zheng, W., Miao, K., Liu, Y., Zhao, Y., Zhang, M., Pan, S. and Dai, Y. (2010). Chemical diversity of biologically active metabolites in the sclerotia of Inonotus obliquus and submerged culture strategies for up-regulating their production. Appl. Microbiol. Biotechnol., 87(4): 1237-54. 